\title{
Influence of Solvent on the Secondary Structure of Helical Poly $(N$-propargyl-(1R)-camphor-10-sulfamide)
}

\author{
By Zhigang ZHANG, ${ }^{1,2,3}$ Jianping DENG, ${ }^{1,2, *}$ Jiewen LI, ${ }^{1,2}$ and Wantai $Y A N G^{1,2, *}$
}

The influence of solvent on the geometrical and secondary structure of poly( $N$-propargyl-(1R)-camphor-10-sulfamide) (poly(1)) was investigated. ${ }^{1} \mathrm{H}$ NMR spectra of poly(1) measured in varied solvent and at varied temperature showed that solvent influenced the mobility of the polymer's main chain. Poly(1) adopted stable helices or disordered states in different solvents. Poly(1) could take helical conformation in toluene. Further characterization showed that hydrogen bond could form between the neighboring sulfamide groups. In mixed solvent comprising toluene and methanol, poly(1) underwent aggregation rather than taking helix when the content of methanol exceeded $40 \mathrm{vol} \%$. In another binary solvent comprising DMSO and chloroform, poly(1) changed gradually from helical to disordered conformation with increasing the content of DMSO.

KEY WORDS: Chiral / Conjugated Polymers / Helical Conformation / Hydrogen Bonding / Poly(N-propargylsulfamides) /

Since Watson and Crick built the double helix hypothesis for DNA, ${ }^{1,2}$ scientists have found that many natural biomacromolecules adopt helix structures such as the double helix of protein and the triple-helix of collagen. ${ }^{3,4}$ By mimicking the naturally occurring macromolecules, scientists synthesized polypeptides, ${ }^{3}$ polypeptoid ${ }^{5}$ and peptide $^{6}$ with helical conformations. With the development of polymer science, chemists have also designed and synthesized a series of completely artificial helical polymers. Synthetic polymers with semiflexible main chain, e.g. substituted polyacetylenes, ${ }^{7}$ polyisocyanates, ${ }^{8}$ and polysilanes, ${ }^{9}$ have thermodynamically controlled helix sense. However, some of the other helical polymers can take stable helix because of their rigid backbones, well exemplified by polychlorals, ${ }^{10}$ polyisocyanides, ${ }^{11}$ and polymethacrylates. ${ }^{12}$ In addition, a certain helical structure is also partly formed for isotactic PVA. ${ }^{13}$

Many substituted polyacetylenes, especially poly( $N$-propargylamides) ${ }^{14}$ and poly(propiolic esters $)^{15}$ can undergo helixdisordered conformation transitions and/or helix-sense inversion when change the solvent composition. Our previous investigations ${ }^{16}$ showed that poly( $N$-propargylsulfamides), one of the substituted polyacetylenes could take helical conformation. However, the effect of solvent composition on the secondary structure of this new class of helical polymer has not been studied. In this paper, we systemically studied the influence of solvent on the secondary structure of poly(1). In binary solvent consisting of toluene and methanol, aggregation behavior took place when the content of methanol exceeded $40 \mathrm{vol} \%$; in another binary solvent consisting of DMSO and chloroform, helical conformation in poly(1) changed into random coil with increasing the content of DMSO. These results clearly demonstrated that the polarity of solvents had large influence on the secondary structure of the polymer. Further more, these results are significant for design and synthesis of other novel helical polymers and also important for practical applications.

\section{EXPERIMENTAL}

\section{Measurements}

${ }^{1} \mathrm{H}$ NMR spectra were recorded on a Bruker AV600 spectrometer. IR spectra were recorded with a Nicolet NEXUS 670 spectrophotometer. Circular dichroism (CD) and UV-vis spectra were recorded on a JASCO J-810 spectropolarimeter equipped with a JULABO heating immersion circulator (ranging from room temperature to $80^{\circ} \mathrm{C}$ ), and with an accessory consisting of a temperature varying cryostat (Model CRYS-416) and a thermo controller (Model TC-22HK) (ranging from room temperature to $-80^{\circ} \mathrm{C}$ ). Specific rotations were measured on a JASCO P-1020 digital polarimeter with a sodium lamp as the light source at room temperature.

\section{Materials}

Solvents were distilled by the standard methods. Propargylamine (Aldrich), and 1R-(-)-10-camphorsulfonyl chloride (Fluka) were used as received without further purification. (nbd) $\mathrm{Rh}^{+} \mathrm{B}^{-}\left(\mathrm{C}_{6} \mathrm{H}_{5}\right)_{4}$ was prepared as reported. ${ }^{17}$

\section{Monomer Synthesis}

Synthesis of monomer $\mathbf{1}$ in Scheme 1 was described in detail earlier. ${ }^{16}$ The main procedures are as follows. $1 R-(-)-10$ camphorsulfonyl chloride $(5 \mathrm{~g}, 20 \mathrm{mmol})$, pyridine $(3.2 \mathrm{~mL}$, $40 \mathrm{mmol})$ and propargylamine $(2.8 \mathrm{~mL}, 40 \mathrm{mmol})$ were added into diethyl ether ( $c a .150 \mathrm{~mL})$ sequentially. The solution was

\footnotetext{
${ }^{1}$ State Key Laboratory of Chemical Resource Engineering, Beijing University of Chemical Technology, Beijing 100029, China

${ }^{2}$ College of Materials Science and Engineering, Beijing University of Chemical Technology, Beijing 100029, China

${ }^{3}$ Hebei Normal University of Science and Technology, Hebei, Qinhuangdao 066004, China

*To whom correspondence should be addressed (Tel: 86-10-6443-5128, Fax: 86-10-6443-5128, E-mail: dengjp@mail.buct.edu.cn (J. P. Deng); Tel: 8610-6443-2262, Fax: 86-10-6441-6338, E-mail: yangwt@ @ail.buct.edu.cn (W. T. Yang)).
} 


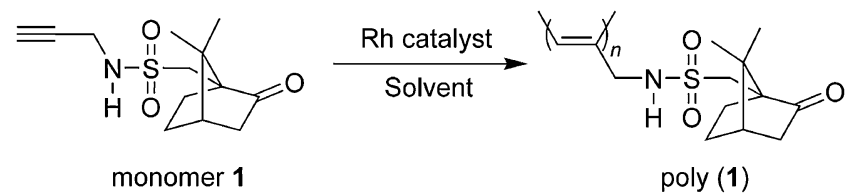

Scheme 1. Polymerization of monomer 1.

stirred overnight firstly at $0{ }^{\circ} \mathrm{C}$ and then at room temperature. Then, a white precipitate formed during the reaction was filtered off. The filtrate was collected and washed with $2 \mathrm{M} \mathrm{HCl}$ three times and with saturated aqueous $\mathrm{NaHCO}_{3}$ solution to neutralize the solution. After that, the solution was dried over anhydrous $\mathrm{MgSO}_{4}$, filtered, and then concentrated to give the crude product. The crude product was then purified by recrystallization twice from $\mathrm{THF}$-hexane to give the target monomer 1, $N$-propargyl-(1R)-camphor-10-sulfamide.

\section{Polymerization}

Polymerization was carried out with (nbd) $\mathrm{Rh}^{+} \mathrm{B}^{-}\left(\mathrm{C}_{6} \mathrm{H}_{5}\right)_{4}$ as the catalyst in dry toluene under nitrogen, [monomer $]_{0}=$ $0.5 \mathrm{M}$, [catalyst] $=5 \mathrm{mM}$. After polymerization, the resulting solution was poured into a large amount of hexane to precipitate the formed polymer. It was filtered and then dried under reduced pressure.

\section{RESULTS AND DISCUSSION}

\section{Geometrical Structure of Poly(1)}

The geometrical structure of poly( $N$-propargyl-( $1 R)$-camphor-10-sulfamide) (poly(1)) was investigated by ${ }^{1} \mathrm{H}$ NMR spectroscopy to examine the stereoregularity of the polymer main chains. The resulting spectra and the assignment of the signals are presented in Figure 1. Measurement with $\mathrm{D}_{2} \mathrm{O}$ exchange (see Figure 1c) was conducted to distinguish $\mathrm{Ha}$ $(=\mathrm{CH})$ from $\mathrm{Hc}(\mathrm{NH})$, and the results showed that the sharp signal around $6.6 \mathrm{ppm}$ was assigned to the proton of the $\mathrm{NH}$ group by comparing Figure $1 \mathrm{~b}$ and 1c. Consequently, the signal around $6.4 \mathrm{ppm}$ was assigned to the main chain's olefinic protons considering that other protons could not appear in the range from 7 to $4.3 \mathrm{ppm}$. By comparing the integrated intensity of the vinyl proton and that of $\mathrm{NCH}_{2}$ peaks, the cis content of the polymer backbones was determined to be approximately $100 \%$. In Figure 1a, the signal around $6.0 \mathrm{ppm}$ may be assigned to the cis-transoid main chain's olefinic prontons. ${ }^{18}$

From Figure 1a, it is easy to find that the signals were broad in toluene; this result is similar to that of poly $(N$-propargyl-

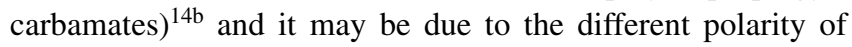
toluene and DMSO. DMSO, as a polar solvent, can destroy the hydrogen bond formed between the neighboring sulfamide groups and thus decreased the rigidity of the polymer chain. ${ }^{14 a}$ In toluene, hydrogen bond is affected little by the solvent, the mobility of the polymer main chains are still limited, resulting in the broader signal at $6.0 \mathrm{ppm}$ in Figure 1a. This assumption was also supported by the liquid-state IR spectrum which will be discussed below in detail. Based on the above discussion,

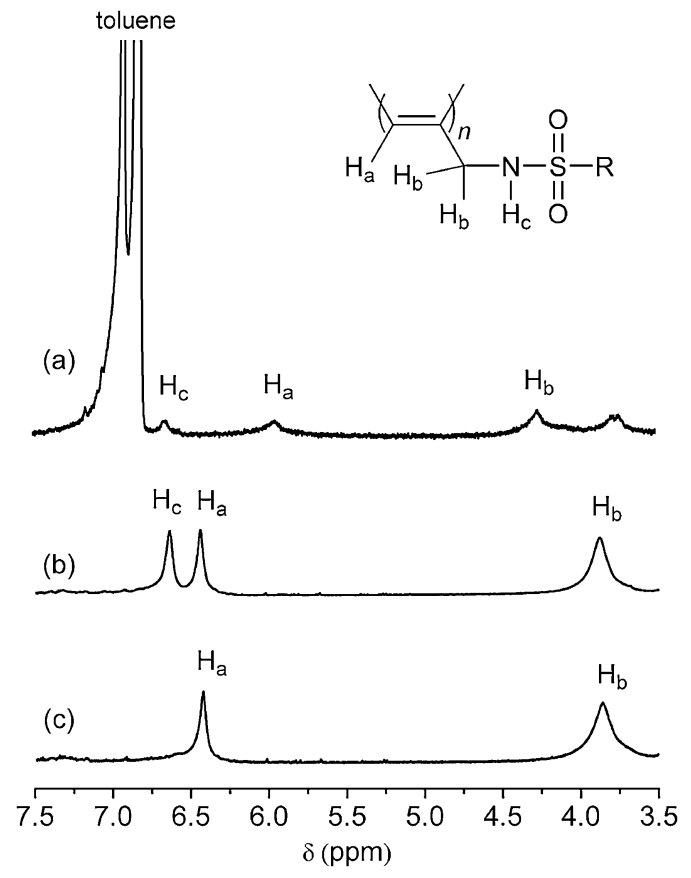

Figure 1. Partial ${ }^{1} \mathrm{H}$ NMR spectra of poly(1) measured in (a) toluene- $d_{8}$ at $55^{\circ} \mathrm{C}$, (b) DMSO- $d_{6}$ at $25^{\circ} \mathrm{C}$, (c) DMSO- $d_{6}$ at $25^{\circ} \mathrm{C}$ with $\mathrm{D}_{2} \mathrm{O}$ exchange.

it is concluded that the broad signal of NMR spectra of poly(1) in toluene- $d_{8}$ is not due to the low stereoregularity but to the limited mobility of the main chain. ${ }^{7 \mathrm{~d}}$ The above result suggested that this polymer had lower mobility of the main chain in nonpolar solvent (e.g., toluene) than that in polar solvent(e.g., DMSO).

\section{Helical Conformation of Poly(1)}

Poly(1) could be dissolved completely in toluene and displayed a large specific rotation $\left([\alpha]_{D}-1883^{\circ}\right.$, in toluene at room temperature, $c=0.070 \mathrm{~g} / \mathrm{dL}$ ) but in opposite sign to that of the corresponding monomer $\mathbf{1}\left([\alpha]_{\mathrm{D}}+32^{\circ}\right.$, in toluene at room temperature, $c=0.080 \mathrm{~g} / \mathrm{dL})$. It is therefore reasonable to assume that poly(1) adopted a helical structure referring to the investigation on poly( $N$-propargylamides $).{ }^{19}$ To confirm this assumption, the variable temperature CD and UV-vis spectra of poly $(\mathbf{1})$ were examined in toluene and illustrated in Figure 2.

As shown in Figure 2a, poly(1) showed obvious signals at around $410 \mathrm{~nm}$ and unconspicuous signals at around $295 \mathrm{~nm}$ (will be discussed in detail below) in CD spectra, which is similar to the case of poly ( $N$-propargylamides $).{ }^{20}$ Referring to the investigations on poly( $N$-propargylamides), we can conclude that poly $(\mathbf{1})$ formed helices with a predominantly one handed screw sense, which resulted in the large specific rotation but in opposite sign to that of monomer 1 . Based on the above result combined with the result of ${ }^{1} \mathrm{H}$ NMR spectra of $\operatorname{poly}(\mathbf{1})$ in toluene, it is concluded that the mobility of polymer's main chain in toluene was low and, thus promoted its adoption of helical structure. Further more, along with the increase of temperature from $-80^{\circ} \mathrm{C}$ to $80^{\circ} \mathrm{C}$, the Cotton 

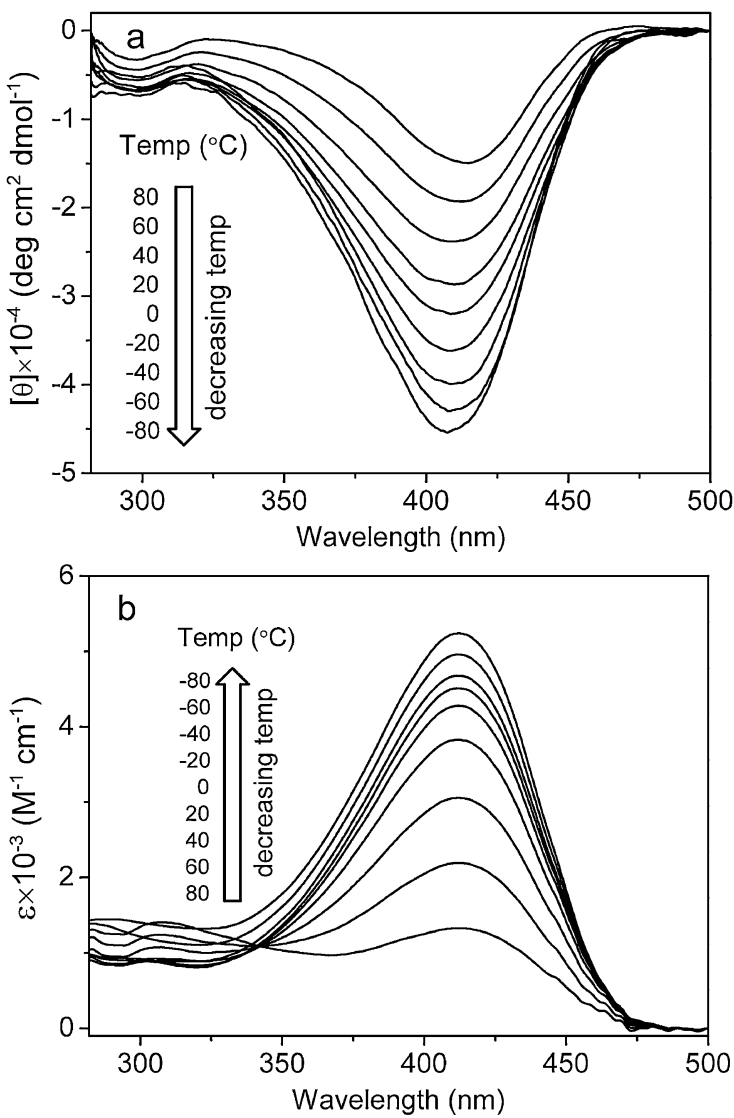

Figure 2. $C D$ (a) and UV-vis (b) spectra of poly(1) at various temperatures (from -80 to $\left.80^{\circ} \mathrm{C}\right)$ in toluene $(c=0.2 \mathrm{mM}$, path length $=5 \mathrm{~mm})$.

effect around $410 \mathrm{~nm}$ did not disappear though the intensity of the peak decreased.

In Figure 2b, UV-vis absorption peaks appeared also around $410 \mathrm{~nm}$, nearly completely corresponding with the CD signals. This phenomenon was also observed in $\operatorname{poly}(N$-propargylamides). ${ }^{18 c, 19 a}$ It is indicated that poly(1) adopted helical conformation under the examined conditions. Similar with the CD spectra, the intensity of the peak around $410 \mathrm{~nm}$ decreased upon increasing temperature from $-80{ }^{\circ} \mathrm{C}$ to $80^{\circ} \mathrm{C}$. Moreover, the intensity of the CD and UV-vis peak around $410 \mathrm{~nm}$ increased with the decrease of temperature. Hence, these processes were completely reversible.

In both of the naturally occurring (for instance, $\mathrm{DNA}^{21}$ ) and the synthetic helical polymers, ${ }^{22}$ hydrogen bond plays important role in stabilizing the helical structure. Poly $(N$-propargylsulfamides) in the present study may form intramolecular hydrogen bond between the neighboring sulfamide groups in the side chains. So liquid-state IR spectroscopics measurements were carried out in toluene to obtain the information on hydrogen bond, as shown in Figure 3. The characteristic peaks of the compounds seem to be very weak without the subtraction of toluene's peak. The horizontal axis was enlarged to show the peaks clearly. The vibrational absorption peaks at 3283, 1328, and $1145 \mathrm{~cm}^{-1}$ in the IR spectrum of poly(1) assigned to $v_{\mathrm{NH}}$, $v_{\mathrm{a}, \mathrm{SO}_{2}}$, and $v_{\mathrm{S}, \mathrm{SO}_{2}}$ respectively can be observed. ${ }^{7 \mathrm{a}, 16}$ When the IR

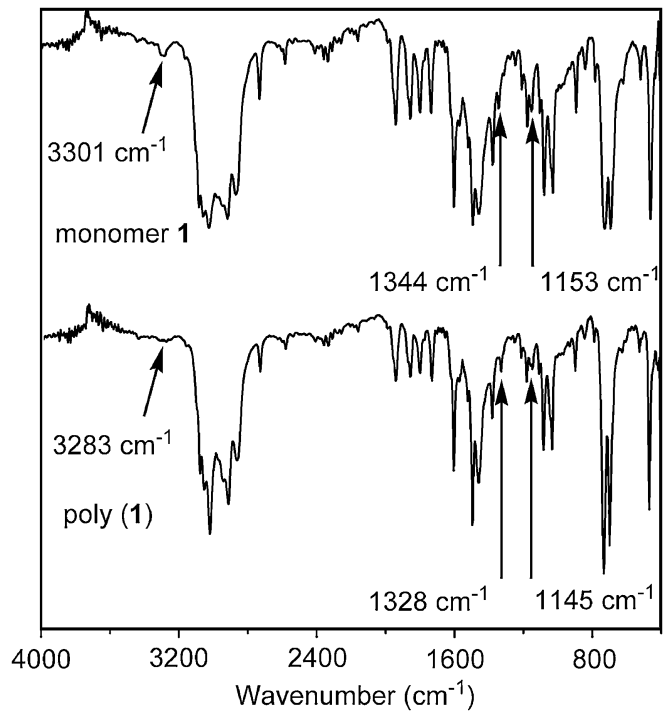

Figure 3. IR spectra of monomer 1 and poly(1) measured in toluene (25 mM) at room temperature.

peaks of poly(1) are compared to those of monomer 1 (3301, 1344 , and $1153 \mathrm{~cm}^{-1}$ respectively), shifts toward lower wavenumbers are obviously demonstrated. These results demonstrated that the sulfamide moieties form hydrogen bonds, which are formed intramolecularly ${ }^{14 b, 18 c, 23}$ because the IR bands were independent of the concentrations between 25 and $80 \mathrm{mM}$. We have ever tried to carry out liquid-state IR spectroscopic measurements of monomer $\mathbf{1}$ and poly(1) in DMSO and $\mathrm{N}, \mathrm{N}$ dimethylformamide; however, it is hardly to obtain useful information on hydrogen bonding because the solvent absorption peaks overlapped those of the compounds.

\section{Conformational Variation Induced by Solvent}

Since the helical structure of poly( $N$-propargylsulfamides) is stabilized by intramolecular hydrogen bond and polar solvent can destroy hydrogen bond, it is likely that the solvent's polarity influence the helical conformation. Thus the CD and UV-vis spectra of poly(1) were measured in toluene/methanol with varied compositions. As shown in Figure 4, the pattern of the CD spectra changed with the addition of methanol. Namely, both plus Cotton effect at $410 \mathrm{~nm}$ and minus Cotton effect at $345 \mathrm{~nm}$ appeared simultaneously. Further more, on one side, the intensity of the two Cotton effects decreased with the increasing of methanol content; on the other side, both of them shifted to long wavelength with increasing the methanol content. Additionally, the color of the solvent became much paler with increasing the content of methanol. When the content of methanol was $40 \%$, the plus signal shifted to $356 \mathrm{~nm}$ and the minus signal shifted to $419 \mathrm{~nm}$, and in the meantime, both the two peaks reached the minimum. Further addition of methanol leads to precipitation of the polymer. Accordingly, from 40 to $100 \%$ of methanol, no change can be detected. Considering the methanol is a poor solvent to $\operatorname{poly}(\mathbf{1})$, it is reasonable to conclude that the apparent bisignate $\mathrm{CD}$ signal and the red shift are due to the aggregation behaviour. ${ }^{24}$ 

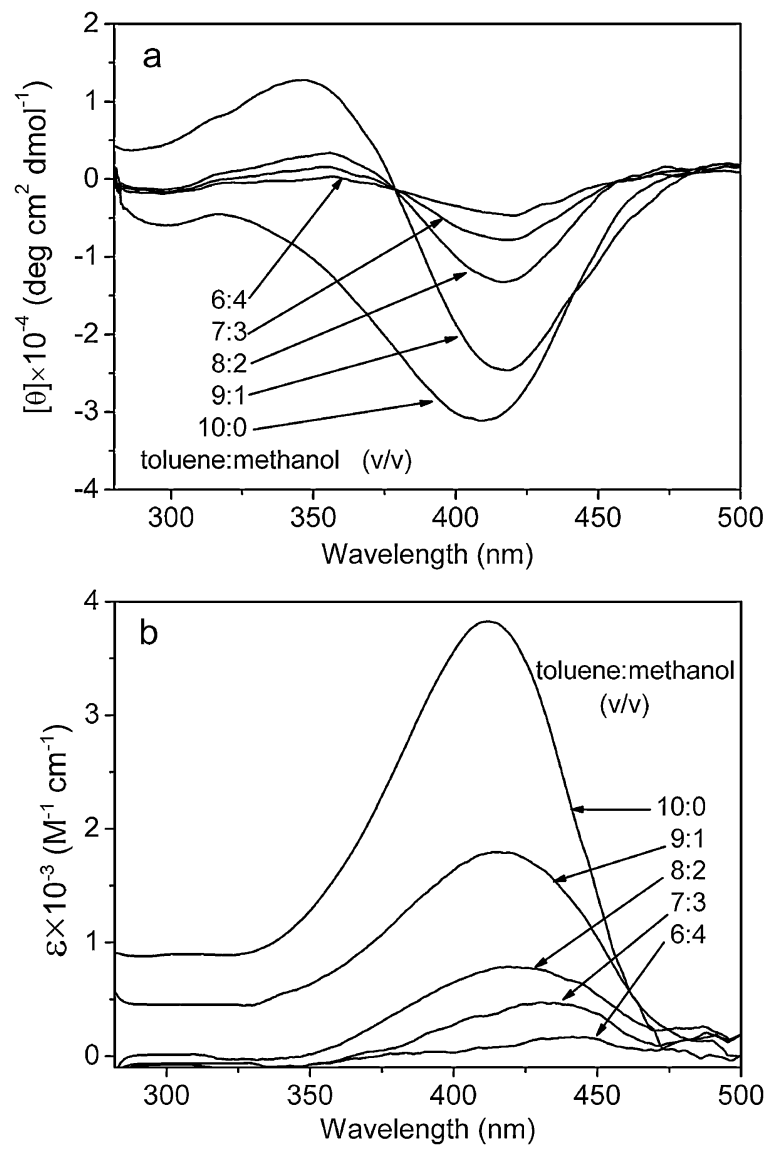

Figure 4. $C D(a)$ and UV-vis (b) spectra of poly(1) in toluene/methanol $(\mathrm{v} / \mathrm{v})$ with various composition at $20^{\circ} \mathrm{C}(c=0.2 \mathrm{mM}$, path length $=5 \mathrm{~mm}$ ).

From Figure $4 b$, it is obvious to find that the intensity of the absorption peaks decreased as increasing the content of methanol in the mixed solvent; meanwhile the absorption peak continuously shifted from $410 \mathrm{~nm}$ to $440 \mathrm{~nm}$. The reduction in magnitude means the helical screw sense reduced. The obvious red shift confirmed that aggregation behavior took place which has been reported previously concerning poly( $p$-phenyleneethynylene). ${ }^{25}$ We failed to detect obvious absorption peak because of the precipitation of the polymer when the content of methanol exceeded $40 \mathrm{vol} \%$. Nevertheless, the conformational variation induced by solvent was reversible in the range from 10:0 to $6: 4$ (toluene: methanol, $\mathrm{v} / \mathrm{v}$ ).

Specific rotations of the polymer in mixed solvent composed of toluene and methanol were measured. From the data in Table I, the absolute value of polymer's specific rotations decreased upon increasing the content of methanol. It may be also caused by aggregation behavior of the polymer.

Table I. Specific rotations of poly(1) in mixed solvent composed of toluene and methanol

\begin{tabular}{ccccccc}
\hline $\begin{array}{c}\text { solvent composition } \\
\text { (toluene:methanol, v:v) }\end{array}$ & $10: 0$ & $9: 1$ & $8: 2$ & $7: 3$ & $6: 4$ & $<6:>4$ \\
\hline$[\alpha]_{\mathrm{D}}(\mathrm{deg})$ & -1883 & -1003 & -62 & -11 & -1 & 0 \\
\hline
\end{tabular}

Measured by polarimeter at room temperature, $c=0.080-0.1 \mathrm{~g} / \mathrm{dL}$
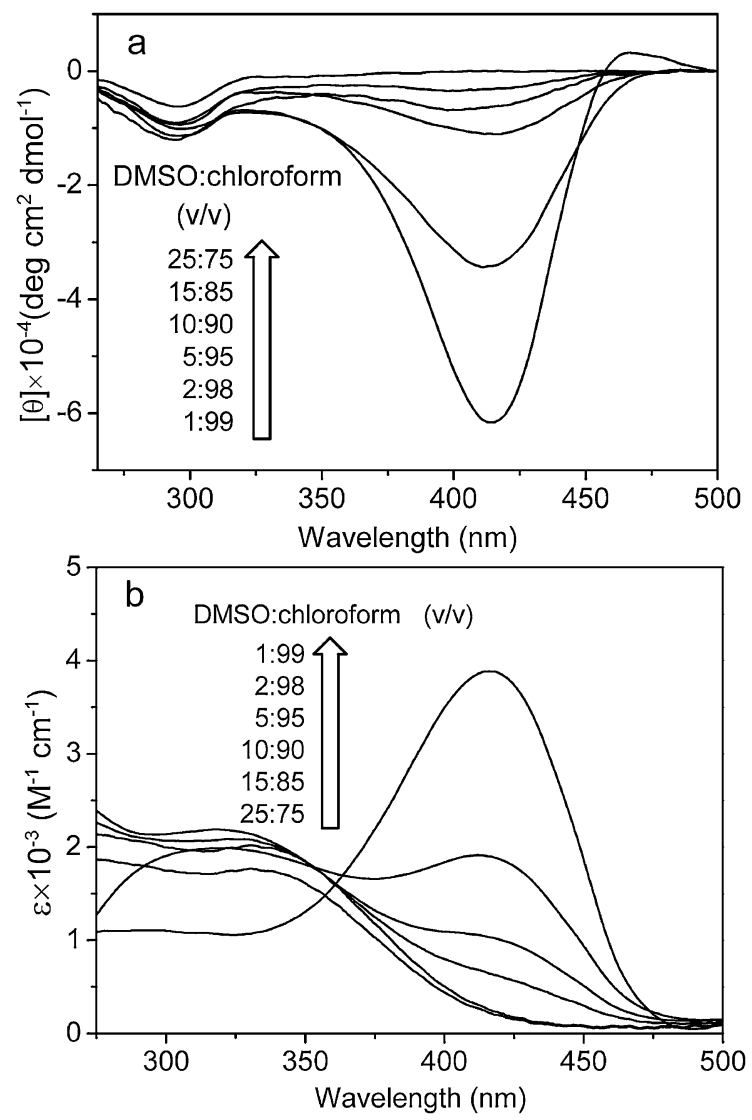

Figure 5. CD (a) and UV-vis (b) spectra of poly(1) in DMSO/chloroform $(\mathrm{v} / \mathrm{v})$ with various composition at $20^{\circ} \mathrm{C}(c=0.2 \mathrm{mM}$, path length $=5 \mathrm{~mm}$ )

In order to further investigate the conformational information of the polymer in solution state, another binary solvent comprising DMSO and chloroform was employed to measure the $\mathrm{CD}$ and $\mathrm{UV}$-vis spectra of poly(1). Figure 5 depicts the changes of $\mathrm{CD}$ and UV-vis spectra upon increasing the content of DMSO in mixed solvent. As shown in Figure 5a, the CD signal around $410 \mathrm{~nm}$ obviously decreased by increasing the content of DMSO in mixed solvent. No distinct CD signal around $410 \mathrm{~nm}$ was obtained for $\geq 25 \mathrm{vol} \%$ of DMSO. It means that the conformational transition from helical to random coil occurred. This should be caused by DMSO. As a polar solvent, DMSO destroyed the hydrogen bond ${ }^{19 b, 26}$ which is the driving force for the polymer to take stable helical conformation. It is considered that the polymer gradually lost the helical structure, as a result of breaking intramolecular hydrogen bond by DMSO.

From Figure 5b, we can find that increasing the content of DMSO in mixed solvent caused the absorption peak around $410 \mathrm{~nm}$ to decrease in magnitude progressively and then disappear; and then a signal around $320 \mathrm{~nm}$ appeared and became stronger simultaneously. When the content of DMSO was $25 \%$ and above, the peak at $410 \mathrm{~nm}$ totally disappeared; in the meantime, the peak at $320 \mathrm{~nm}$ reached the maximum. These results confirm the conclusion that the polymer changed from 
Table II. Specific rotations of poly(1) in mixed solvent composed of DMSO and $\mathrm{CHCl}_{3}$

\begin{tabular}{cccccccc}
\hline $\begin{array}{l}\text { solvent composition } \\
\left(\mathrm{DMSO}: \mathrm{CHCl}_{3}, \mathrm{v}: \mathrm{v}\right)\end{array}$ & $1: 99$ & $2: 98$ & $5: 95$ & $10: 90$ & $15: 85$ & $25: 75$ & $>25:<75$ \\
\hline$[\alpha]_{\mathrm{D}}(\mathrm{deg})$ & -2060 & -1208 & -80 & -42 & -15 & 0 & 0 \\
\hline
\end{tabular}

Measured by polarimeter at room temperature, $c=0.080-0.1 \mathrm{~g} / \mathrm{dL}$

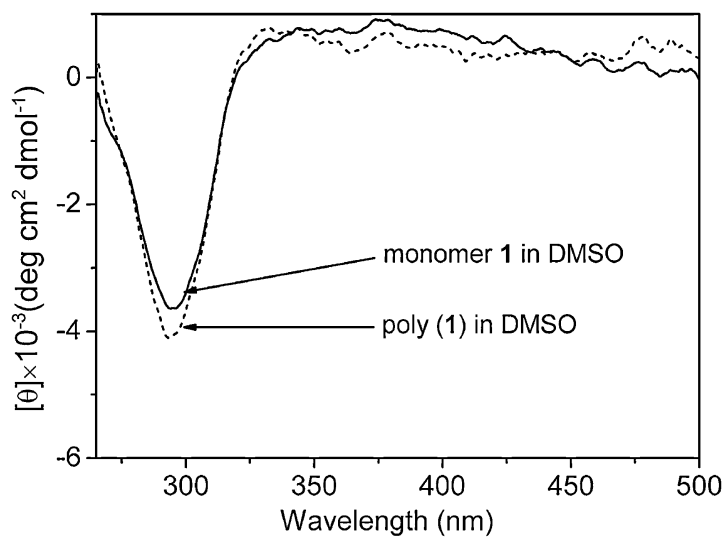

Figure 6. CD spectra of monomer 1 and poly(1) in DMSO measured at $20^{\circ} \mathrm{C}$ $(c=0.2 \mathrm{mM}$, path length $=5 \mathrm{~mm})$.

helical conformation to random coil with the effect of polar solvent. Specific rotations of the polymer in mixed solvent composing of DMSO and chloroform were measured. As shown in Table II, the absolute value of polymer's specific rotations decreased upon increasing the content of DMSO in mixed solvent. This result further confirmed the above conclusions.

From Figure 5a, we can find that only one peak around $295 \mathrm{~nm}$ appeared when the content of the DMSO was more than $25 \%$ (volume ratio). The peak probably arouse from the chiral pendent group. ${ }^{9,27}$ It could be confirmed by comparing the CD spectra of monomer 1 and the corresponding polymer measured in DMSO. From Figure 6, we can easily find that both the monomer and the polymer have only one signal at about $295 \mathrm{~nm}$. Considering that the conjugated backbone can not exist in the monomer and DMSO destroy hydrogen bond which is the key driving force for poly( $N$-propargylsulfamides) to adopt helical conformations, it is reasonable to conclude that the signals at $295 \mathrm{~nm}$ are assigned to the chiral pendent groups in the polymer.

\section{CONCLUSION}

In this report, we studied the influence of solvent on the primary and secondary structure of $\operatorname{poly}(N$-propargylsulfamides). From the result of ${ }^{1} \mathrm{H}$ NMR spectra and $\mathrm{CD}$ and UV-vis spectra of poly(1) in varied solvents, we can concluded that the solvent influenced the mobility of the polymer's main chain and further decided whether the polymer can form helix. Results of CD and UV-vis spectra showed that the polymer took stable helix even at a temperature as high as $80^{\circ} \mathrm{C}$ in toluene. Liquid-state IR spectra measured in toluene showed that hydrogen bond formed between the neighboring sulfamide groups. Both of the two results supported the conclusion deduced from ${ }^{1} \mathrm{H}$ NMR spectra. Moreover, solvent composition can change the secondary structure of the polymer and tune the content of helix. In binary solvent comprising toluene and methanol, aggregation behavior took place when the content of methanol exceeded $40 \mathrm{vol} \%$.

Acknowledgment. We gratefully thank the National Science Foundation of China (20574004), "Specialized Research Fund for the Doctoral Program of Higher Education" (20060010001), "Program for New Century Excellent Talents in University" (NCET-06-0096), and “The Project Sponsored by the Scientific Research Foundation for the Returned Overseas Chinese Scholars, State Education Ministry (China)" for financial support of this work.

Received: November 13, 2007 Accepted: January 27, 2008 Published: March 12, 2008

\section{REFERENCES}

1. J. D. Watson and F. H. C. Crick, Nature, 171, 737 (1953).

2. L. S. Robert, in "The Strands of a Life: The Science of DNA and the Art of Education" Berkeley University of California Press, London, 1994, p 119.

3. T. Kishimoto, Y. Morihara, M. Osanai, S. Ogata, M. Kamitakahara, C. Ohtsuki, and M. Tanihara, Biopolymers, 79, 163 (2005).

4. S. D. Mooney, P. A. Kollman, and T. E. Klein, Biopolymers, 64, 63 (2002).

5. T. J. Sanborn, C. W. Wu, R. N. Zuckermann, and A. E. Barron, Biopolymers, 63, 12 (2002).

6. E. Andreetto, C. Peggion, M. Crisma, and C. Toniolo, Biopolymers (Peptide Science), 84, 490 (2006).

7. a) J. Deng, J. Tabei, M. Shiotsuki, F. Sanda, and T. Masuda, Macromolecules, 37, 5538 (2004).

b) J. Deng, J. Tabei, M. Shiotsuki, F. Sanda, and T. Masuda, Macromol. Chem. Phys., 205, 1103 (2004).

c) J. Deng, J. Tabei, M. Shiotsuki, F. Sanda, and T. Masuda, Macromolecules, 37, 5149 (2004).

d) R. Nomura, J. Tabei, and T. Masuda, Macromolecules, 35, 2955 (2002) and references 20, 21.

e) J. W. Y. Lam and B. Z. Tang, Acc. Chem. Res., 38, 745 (2005).

f) J. Deng, J. Tabei, M. Shiotsuki, F. Sanda, and T. Masuda, Macromolecules, 37, 1891 (2004).

g) J. Deng, J. Tabei, M. Shiotsuki, F. Sanda, and T. Masuda, Macromolecules, 37, 7156 (2004).

h) J. Deng, J. Tabei, M. Shiotsuki, F. Sanda, and T. Masuda, Macromolecules, 37, 9715 (2004).

8. a) S. K. Jha, K. S. Cheon, M. M. Green, and J. V. Selinger, J. Am. Chem. Soc., 121, 1665 (1999).

b) M. M. Green, J. W. Park, T. Sato, A. Teramoto, S. Lifson, R. L. B. Selinger, and J. V. Selinger, Angew. Chem. Int. Ed., 38, 3138 (1999). c) Y. Okamoto, M. Matsuda, T. Nakano, and E. Yashima, J. Polym. Sci., Part A: Polym. Chem., 32, 309 (1994).

d) S. Mayer and R. Zentel, Prog. Polym. Sci., 26, 1973 (2001).

e) R. Sakai, I. Otsuka, T. Satoh, R. Kakuchi, H. Kaga, and T. Kakuchi, J. Polym. Sci., Part A: Polym. Chem., 44, 325 (2006).

9. a) H. Nakashima, M. Fujiki, and J. R. Koe, Macromolecules, 32, 7707 (1999).

b) M. Fujiki, J. Am. Chem. Soc., 116, 11976 (1994).

c) A. Saxena, R. Rai, A. Ohira, and M. Fujiki, J. Polym. Sci., Part A: 
Polym. Chem., 42, 4518 (2004).

10. K. Ute, K. Hirose, H. Kashimoto, K. Hatada, and O. Vogl, J. Am. Chem. Soc., 113, 6305 (1991).

11. a) Y. Ito, T. Ohara, R. Shima, and M. Suginome, J. Am. Chem. Soc., 118, 9188 (1996).

b) F. Takei, H. Hayashi, K. Onitsuka, N. Kobayashi, and S. Takahashi, Angew. Chem. Int. Ed., 40, 4092 (2001).

c) J. J. L. M. Cornelissen, W. S. Graswinckel, A. E. Rowan, N. A. J. M. Sommerdijk, and R. J. M. Nolte, J. Polym. Sci., Part A: Polym. Chem., 41, 1725 (2003).

12. a) T. Nakano and Y. Okamoto, Chem. Rev., 101, 4013 (2001).

b) Y. Okamoto and T. Nakano, Chem. Rev., 94, 349 (1994).

c) Y. Okamoto, K. Suzuki, K. Ohta, K. Hatada, and H. Yuki, J. Am. Chem. Soc., 101, 4763 (1979).

13. a) K. Masuda and F. Horii, Macromolecules, 31, 5810 (1998).

b) H. Ohgi, T. Sato, S. Hu, and F. Horii, Polymer, 47, 1324 (2006).

14. a) F. Sanda, S. Nishiura, M. Shiotsuki, and T. Masuda, Macromolecules, 38, 3075 (2005).

b) R. Nomura, S. Nishiura, J. Tabei, F. Sanda, and T. Masuda, Macromolecules, 36, 5076 (2003).

15. H. Nakako, R. Nomura, and T. Masuda, Macromolecules, 34, 1496 (2001).

16. Z. Zhang, J. Deng, W. Zhao, J. Wang, and W. Yang, J. Polym. Sci., Part A: Polym. Chem., 45, 500 (2007).

17. R. R. Schrock and J. A. Osborn, Inorg. Chem., 9, 2339 (1970).

18. a) T. Nishimura, K. Maeda, S. Ohsawa, and E. Yashima, Chem. Eur. J., 11, 1181 (2005).

b) C. I. Simionescu, V. Percec, and S. Dumitrescu, J. Polym. Science., Polym. Chem. Ed., 15, 2497 (1977).

c) R. Nomura, J. Tabei, and T. Masuda, J. Am. Chem. Soc., 123, 8430 (2001). d) M. Tabata, T. Sone, and Y. Sadahiro, Macromol. Chem. Phys., 200, 265 (1999).

e) Y. Kishimoto, P. Eckerle, T. Miyatake, M. Kainosho, A. Ono, T. Ikariya, and R. Noyori, J. Am. Chem. Soc., 121, 12035 (1999).

19. a) J. Tabei, R. Nomura, F. Sanda, and T. Masuda, Macromolecules, 36, 8603 (2003).

b) J. Tabei, R. Nomura, F. Sanda, and T. Masuda, Macromolecules, 37, 1175 (2004).

20. J. Tabei, M. Shiotsuki, F. Sanda, and T. Masuda, Macromolecules, 38, 9448 (2005).

21. V. F. Morozov, A. V. Badasyan, A. V. Grigoryan, M. A. Sahakyan, and Y. S. Mamasakhlisov, Biopolymers, 75, 434 (2004).

22. J. J. van Gorp, J. A. J. M. Vekemans, and E. W. Meijer, Chem. Commun., 4, 60 (2004).

23. a) R. Nomura, J. Tabei, S. Nishiura, and T. Masuda, Macromolecules, 36, 561 (2003).

b) J. Tabei, M. Shiotsuki, F. Sanda, and T. Masuda, Macromolecules, 38, 5860 (2005).

c) T. Fujii, M. Shiotsuki, Y. Inai, F. Sanda, and T. Masuda, Macromolecules, 40, 7079 (2007).

24. H. Z. Tang, M. Fujiki, and T. Sato, Macromolecules, 35, 6439 (2002).

25. R. Fiesel, C. E. Halkyard, M. E. Rampey, L. Kloppenburg, S. L. Studer-Martinez, U. Scherf, and U. H. F. Bunz, Macromol. Rapid. Commun., 20, 107 (1999).

26. a) H. Zhao, F. Sanda, and T. Masuda, J. Polym. Sci., Part A: Polym. Chem., 43, 5168 (2005).

b) G. Gao, F. Sanda, and T. Masuda, Macromolecules, 36, 3932 (2003).

c) H. Zhao, F. Sanda, and T. Masuda, Polymer, 46, 2841 (2005).

27. T. Aoki, T. Kaneko, N. Maruyama, A. Sumi, M. Takahashi, T. Sato, and M. Teraguchi, J. Am. Chem. Soc., 125, 6346 (2003). 